\title{
Circulating Markers of Inflammation and Their Link to Indices of Adiposity
}

\author{
Lucy M. Browning ${ }^{a} \quad$ Jeremy D. Krebs ${ }^{a} \quad$ Edel C. Magee $^{a}$ Gema Frühbeck $^{b}$ Susan A. Jebb \\ ${ }^{a}$ MRC Human Nutrition Research, Elsie Widdowson Laboratory, Cambridge, UK \\ ${ }^{b}$ Metabolic Research Laboratory, Clinica Universitaria, University of Navarra, Pamplona, Spain
}

\section{Key Words}

Obesity · Inflammation - Adipokines · Metabolism . Cytokines · Metabolic syndrome

\section{Summary}

Background: Adipose tissue produces a number of inflammatory mediators. Circulating concentrations of these inflammatory markers are increasingly used as markers of local or systemic inflammation. This study compares results for 3 inflammatory adipokines measured using 2 techniques, (multiplex and ELISA), and determines the relationships with C-reactive protein (CRP), obesity, and the impact of moderate weight loss. Subjects and Methods: Fasting blood samples were collected at baseline and after a 24-week weight loss intervention. Interleukin 6 (IL-6), tumour necrosis factor $\alpha$ (TNF$\alpha)$, and monocyte chemoattractant protein 1 (MCP-1) were measured using a standard ELISA technique or a new multiplex technique. A total of 54 women with complete data were included in this analysis. Results: Multiplex showed poor correlation with ELISA results, and were not significantly correlated with CRP. Using ELISA data, IL-6 and CRP were significantly correlated with body mass index (BMI) ( $r=0.42$ and $r=0.55)$, but MCP-1 and TNF- $\alpha$ were not $(r=-0.07$ and $r=0.06)$. Changes in MCP-1, TNF- $\alpha$, and IL- 6 were not significantly different between control and weight loss groups. CRP was significantly reduced in weight loss vs. control group ( $p<$ 0.05), and change in CRP correlated with change in BMI ( $r=0.31)$. Conclusion: Circulating IL-6 and CRP, but not MCP-1 and TNF- $\alpha$, are significantly associated with indices of adiposity in obese women. This study suggests that circulating IL- 6 and CRP, but not MCP- 1 and TNF- $\alpha$, are useful markers of obesity-related inflammation.

\section{Introduction}

Obesity is associated with a number of circulating markers of inflammation including the cytokines interleukin 6 (IL-6) and tumour necrosis factor $\alpha(\mathrm{TNF}-\alpha)$, and acute phase markers C-reactive protein (CRP), fibrinogen, and sialic acid [1-3]. Novel multiplex techniques are now available to measure multiple cytokines. They have the advantage over traditional techniques of being able to offer multiple results, on a small sample volume, within a single test. However, the precision of the results for human plasma/serum samples is not clear. It is hypothesised that these circulating markers are indicative of inflammatory processes within adipose tissue, since adipose tissue has been shown to produce a number of these inflammatory mediators $[4,5]$. Recent evidence suggests that as fat accumulates in adipose tissue, macrophages infiltrate the site, producing cytokines and contributing to the systemic pro-inflammatory state observed in obese subjects $[6,7]$. Monocyte chemoattractant protein 1 (MCP-1), a protein responsible for recruiting macrophages, is produced by adipose tissue, and in morbidly obese subjects adipose tissue expression of MCP-1 is correlated with obesity [8].

Diet- and surgery-induced weight loss are effective strategies to reduce obesity-related inflammation [9-12], and are associated with improvements in a number of co-morbidities, including insulin resistance, hypertension, and dyslipidaemia [13-15]. Adipose tissue MCP-1 mRNA is significantly reduced by large weight losses (mean $22.1 \mathrm{~kg}$ ) following bariatric surgery [8]. Reductions in circulating MCP-1 have been shown to be significantly reduced following similarly large (mean $18.9 \mathrm{~kg}$ ) weight losses in morbidly obese subjects on an acute weight loss dietary intervention [16]. However, the impact of moderate weight loss on circulating MCP-1 concentrations has not been determined in a controlled study. This study will compare the results obtained from both traditional ELISA tech-

\section{KARGER}

Fax +497614520714

Information@Karger.de

www.karger.com (c) 2008 S. Karger GmbH, Freiburg

Accessible online at:

www.karger.com/ofa
Dr. Lucy M. Browning

MRC Human Nutrition Research, Elsie Widdowson Laboratory

Fulbourn Road, Cambridge, CB1 9NL, UK

Tel. +44 1223 4-26356, Fax -37515

Lucy.Browning@mrc-hnr.cam.ac.uk 
niques and multiplex techniques for 3 inflammatory markers of interest, and go on to explore the relationships between circulating inflammatory markers and measures of obesity.

\section{Subjects and Methods}

\section{Population}

Overweight female subjects were recruited from the community to participate in a 24-week randomised controlled intervention study at MRC Human Nutrition Research. The study was carried out in accordance with the Declaration of Helsinki (2000) of the World Medical Association, and was approved by the Cambridge Local Research Ethics Committee. All subjects gave written informed consent. Subjects were overweight or obese (body mass index (BMI) $>27 \mathrm{~kg} / \mathrm{m}^{2}$ ) and hyperinsulinaemic at a screening appointment (fasting plasma insulin $>70 \mathrm{pmol} / \mathrm{l}$ ). Subjects were excluded if they were pregnant, had symptoms of intercurrent infection, known diabetes, a chronic inflammatory condition, treated dyslipidaemia, liver disease, or malignancy. Smokers, subjects with excessive alcohol consumption (greater than 25 units per week), and those taking non-steroidal anti-inflammatory drugs (NSAIDs), steroids, or oil supplements were excluded.

\section{Study Design}

The design and main findings of the study have been described previously [17]. Briefly, subjects were randomly assigned to either a control group (no weight loss and placebo oil) or 1 of 2 weight loss intervention groups prescribed either supplemental long-chain (LC) n-3 PUFA or placebo oil ( $5 \mathrm{~g}$ per day comprising either $1.3 \mathrm{~g}$ eicosapentaenoic acid and $2.9 \mathrm{~g}$ docosahexaenoic acid, or $2.8 \mathrm{~g}$ linoleic acid and $1.4 \mathrm{~g}$ oleic acid). For the purposes of the present study, both weight loss groups have been analysed together. The weight loss programme was designed to achieve a $10 \%$ weight loss in 12 weeks, followed by a 12 -week weight maintenance phase. Investigations included weight and body composition measurements. Fasting blood collections were made at baseline and 24 weeks. A total of 93 women completed the intervention study; 74 women were included in the comparison study of the 2 methods. Subjects without adequate sample volumes remaining or a coefficient of variation $(\mathrm{CV})$ of greater than $10 \%$ between duplicates for all adipokine measurements were excluded. A total of 54 women remained in the analysis of the relationship between circulating adipokines and obesity before and after weight loss. For the analysis of weight loss data, 14 women were randomised to the control group and 40 to the weight loss group.

\section{Weight Loss Programme}

Subjects in the weight loss groups attended fortnightly group sessions where they received detailed advice regarding dietary composition and total energy intake. These subjects also received standard advice to increase their physical activity. Subjects were advised to consume an energyrestricted diet of approximately 3.3-3.8 MJ/day (800-900 kcal/day), predominantly of semi-skimmed milk for the first 5 weeks to facilitate acute weight loss. This was followed by a staged re-introduction of meals so that by the end of 12 weeks subjects were prescribed a diet providing sufficient energy to match their maintenance energy requirements (approximately $2,500 \mathrm{kcal} / \mathrm{day}$ ) and a prescribed composition of $15 \%$ protein, $35 \%$ fat, and $50 \%$ carbohydrate. The control group received no dietary advice.

\section{Methods}

Weight was measured to the nearest $10 \mathrm{~g}$ using a digital scale. Height was measured to the nearest $0.5 \mathrm{~cm}$ using a wall-mounted stadiometer. Waist circumference was taken as the smallest circumference between the lower costal margin and the pelvic brim measured to the nearest $0.5 \mathrm{~cm}$. Body fat mass and abdominal fat mass were measured using dual X-ray absorp-
Table 1. Baseline subject characteristics $(n=54)$

\begin{tabular}{lrrl}
\hline & Mean & SD & Range \\
\hline Age, years & 44.5 & 13.1 & $21.0-69.0$ \\
Weight, kg & 94.7 & 16.1 & $70.0-129.1$ \\
Waist circumference, cm & 99.8 & 11.2 & $76.0-125.5$ \\
BMI, kg/m ${ }^{2}$ & 35.8 & 6.0 & $27.2-47.6$ \\
DXA fat mass, kg & 45.9 & 13.0 & $27.1-71.2$ \\
DXA abdominal fat, kg & 6.9 & 2.8 & $3.2-13.6$ \\
CRP $^{\text {a }} \mathrm{mg} / \mathrm{l}$ & 3.8 & 5.0 & $0.7-23.4$ \\
IL-6 $^{2}, \mathrm{pg} / \mathrm{ml}$ & 2.9 & 3.3 & $0.6-21.7$ \\
TNF- $\alpha^{\mathrm{a}}, \mathrm{pg} / \mathrm{ml}$ & 2.6 & 3.3 & $0.1-18.9$ \\
MCP- $1, \mathrm{pg} / \mathrm{ml}$ & 236.3 & 72.9 & $96.6-417.1$ \\
\hline
\end{tabular}

${ }^{a}$ Variables $\log _{\mathrm{e}}$ transformed before analysis.

tiometry (DXA) on a Hologic QDR-100W scanner (Hologic Inc. Waltham, MA, USA). A measurement of abdominal fat was calculated by isolating the section between the L2 and L4 lumbar vertebrae. All assays were completed in duplicate, with results rejected if the intra-individual $\mathrm{CV}$ was greater than $10 \%$. Fasting plasma and serum samples were collected for inflammation assays. IL-6 and TNF- $\alpha$ were measured using high sensitivity ELISA assays (Quantikine kit, R and D Systems, Abingdon, UK), and MCP-1 using an ELISA method (Quantikine kit, R and D Systems). Limits of detection are published at $0.04 \mathrm{pg} / \mathrm{ml}, 0.1 \mathrm{pg} / \mathrm{ml}$, and $5 \mathrm{pg} / \mathrm{ml}$, respectively. TNF- $\alpha$, IL- 6 , and MCP-1 were also measured using a bead-based luminex technique, on a human 17-plex panel (BioRad, Hercules, CA, USA). Limits of detection are published at $10 \mathrm{pg} / \mathrm{ml}$ for all 17 cytokines. Standard dilutions were run to $2 \mathrm{pg} / \mathrm{ml}$. CRP was measured using a high sensitivity assay (Dade-Behring, Walton, UK) as an independent index of inflammation.

\section{Statistics}

Data was analysed using SPSS (SPSS Inc., Chicago, IL, USA). Where necessary, data was $\log _{\mathrm{e}}$ transformed to normalise distributions before analysis, and is expressed as mean and standard deviation (SD) for normally distributed data, or as geometric mean and SD (calculated before transformation) for transformed data. Bland Altman analysis was used to assess the agreement between the 2 methods for each adipokine, with Pearson's correlation coefficients to explore relationships at baseline or the change in variables with the intervention. Simple statistical comparisons between control and weight loss groups were made using t-tests.

\section{Results}

\section{Comparison of the Two Methods}

Baseline TNF- $\alpha$ was undetectable in 63 out of 74 subjects using the luminex method. Bland Altman plots showed poor agreement between the 2 methods for all 3 inflammatory markers (graphs not shown), and correlations were poor (IL-6 $r=-0.11$, TNF- $\alpha r=0.16$, MCP-1 $r=0.42$ ) (fig. 1). None of the luminex results were significantly correlated with CRP, the independent index of inflammation, while IL-6, measured by ELISA, was significantly related $(\mathrm{r}=0.45, \mathrm{p}<0.01)$. For this reason, ELISA inflammatory marker data was used for all further analyses. 
Table 2. Relationship between obesity and measures of inflammation at baseline $^{\mathrm{a}}$
Table 3. Relationship between change in obesity and change in measures of inflammation ${ }^{\mathrm{a}}$

\begin{tabular}{|c|c|c|c|c|c|c|c|c|}
\hline & BMI & $\begin{array}{l}\text { Waist } \\
\text { circumference }\end{array}$ & Fat mass & $\begin{array}{l}\text { Abdominal } \\
\text { fat mass }\end{array}$ & $\mathrm{CRP}^{\mathrm{b}}$ & IL-6 ${ }^{\mathrm{b}}$ & $\mathrm{TNF}-\alpha^{\mathrm{b}}$ & MCP-1 \\
\hline \multicolumn{9}{|l|}{ BMI } \\
\hline Waist circumference & $0.86 * * *$ & & & & & & & \\
\hline DXA fat mass & $0.92 * * *$ & $0.80 * * *$ & & & & & & \\
\hline Abdominal fat mass & $0.90 * * *$ & $0.86 * * *$ & $0.91 * * *$ & & & & & \\
\hline $\mathrm{CRP}^{\mathrm{b}}$ & $0.55 * * *$ & $0.50 * * *$ & $0.48 * * *$ & $0.47 * * *$ & & & & \\
\hline IL-6 ${ }^{\mathrm{b}}$ & $0.42 * *$ & $0.44 * *$ & $0.36 * *$ & $0.45^{* *}$ & $0.33 *$ & & & \\
\hline TNF- $\alpha^{b}$ & 0.06 & 0.04 & 0.07 & -0.06 & 0.15 & 0.10 & & \\
\hline MCP-1 & -0.07 & 0.12 & 0.04 & 0.06 & -0.01 & 0.05 & 0.08 & \\
\hline
\end{tabular}

aData presented as Pearson's correlation coefficient.

bVariables $\log _{\mathrm{e}}$ transformed before analysis.

$* \mathrm{p}<0.05$.

$* * \mathrm{p}<0.01$

$* * * \mathrm{p}<0.0001$

\begin{tabular}{|c|c|c|c|c|c|c|c|c|}
\hline & BMI & $\begin{array}{l}\text { Waist } \\
\text { circumference }\end{array}$ & Fat mass & $\begin{array}{l}\text { Abdominal } \\
\text { fat mass }\end{array}$ & CRP & IL-6 & $\mathrm{TNF}-\alpha$ & MCP-1 \\
\hline \multicolumn{9}{|l|}{ BMI } \\
\hline Waist circumference & $0.81 * * *$ & & & & & & & \\
\hline Fat mass & $0.96^{* * *}$ & $0.82 * * *$ & & & & & & \\
\hline Abdominal fat mass & $0.88 * * *$ & $0.77 * * *$ & $0.95 * * *$ & & & & & \\
\hline CRP & $0.31^{*}$ & $0.28 *$ & $0.35^{* *}$ & $0.38 * *$ & & & & \\
\hline IL-6 & 0.13 & -0.10 & 0.09 & 0.11 & $0.37 * *$ & & & \\
\hline TNF- $\alpha$ & -0.07 & -0.04 & -0.06 & -0.03 & 0.20 & 0.23 & & \\
\hline MCP-1 & 0.11 & 0.07 & 0.07 & -0.01 & 0.00 & 0.16 & -0.05 & \\
\hline
\end{tabular}

aData presented as Pearson's correlation coefficient.

$* \mathrm{p}<0.05$.

$* * \mathrm{p}<0.01$

$* * * \mathrm{p}<0.0001$

\section{Baseline Assessment}

The baseline characteristics of subjects who completed the study are shown in table 1 . All women were overweight, with a weight in the range 70.0-129.1 kg (mean 94.7 $\pm 16.1 \mathrm{~kg}$ ), BMI range $27.2-47.6 \mathrm{~kg} / \mathrm{m}^{2}$ (mean $35.8 \pm 6.0 \mathrm{~kg} / \mathrm{m}^{2}$ ), with a body fat percentage in the range $35.0-61.4 \%$ (mean $47.7 \pm$ $6.3 \%$ ), and aged between 21 and 69 years (mean $44.5 \pm 13.1$ years). Figure 2 shows the relationships between markers of inflammation and BMI at baseline. Correlation coefficients showed that IL-6 and CRP were significantly correlated with each other $(\mathrm{r}=0.33, \mathrm{p}<0.05)$ and with BMI, waist circumference, total fat mass, or abdominal fat mass (table $2 ; \mathrm{p}<0.01$ for all comparisons). In contrast, there was no significant relationship between MCP-1 or TNF- $\alpha$ and any of the indices of obesity (table $2 ; \mathrm{p}>0.05$ ). Neither MCP-1 nor TNF- $\alpha$ were significantly associated with any of the other circulating adipokines.

\section{Effect of Weight Loss on Markers of Adipose Tissue \\ Inflammation}

The change in weight, BMI, waist circumference, total fat mass, and abdominal fat mass were significantly different between the weight loss and control groups ( $p<0.0001$ for all), with a mean difference in weight of $10.8 \mathrm{~kg}$, BMI of $4.1 \mathrm{~kg} / \mathrm{m}^{2}$, waist circumference of $11.1 \mathrm{~cm}$, total fat mass of $10.9 \mathrm{~kg}$, and abdominal fat mass of $2.1 \mathrm{~kg}$. Table 3 shows the relationships between changes in measures of obesity, and changes in adipokine concentrations. The change in CRP was significantly different between the weight loss and control groups ( $\mathrm{p}<$ $0.05)$. In contrast, there were no significant differences in the change in MCP-1, TNF- $\alpha$, or IL- 6 between the weight loss and control groups ( $\mathrm{p}=0.48, \mathrm{p}=0.44$, and $\mathrm{p}=0.62$, respectively). Changes in MCP-1 and TNF- $\alpha$ were not significantly correlated with any other changes. The change in CRP was significantly correlated with the change in adiposity (table 3 ). Change in 

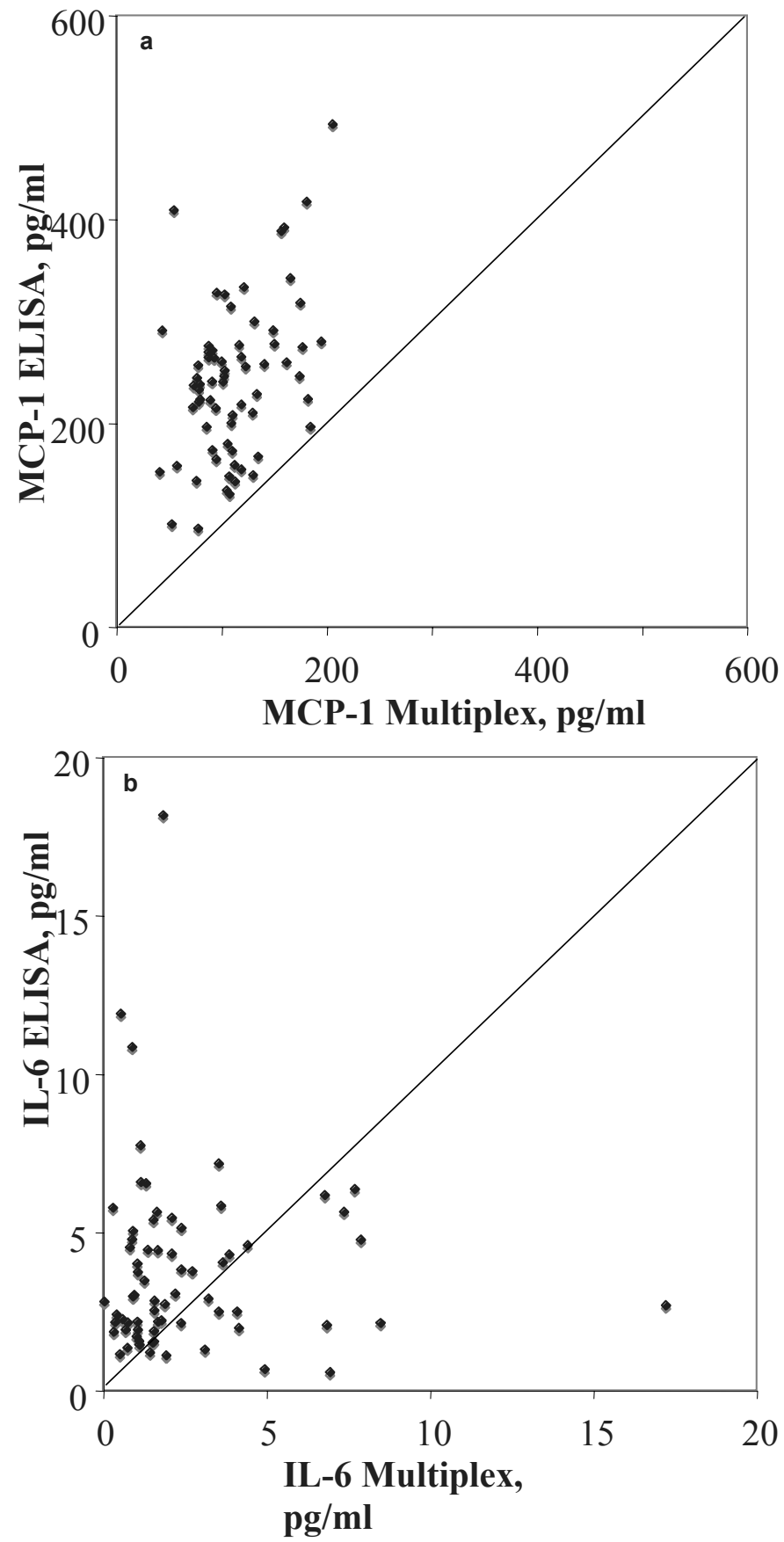

IL-6 was not significantly correlated with the indices of obesity, although it was significantly correlated with the change in CRP $(r=0.37, p<0.01)$.

\section{Discussion}

This study has shown that despite the advantage of being able to analyse a single sample for multiple results at once, the multiplex technique results do not correlate well with results obtained using traditional ELISAs. Multiplex results also do not

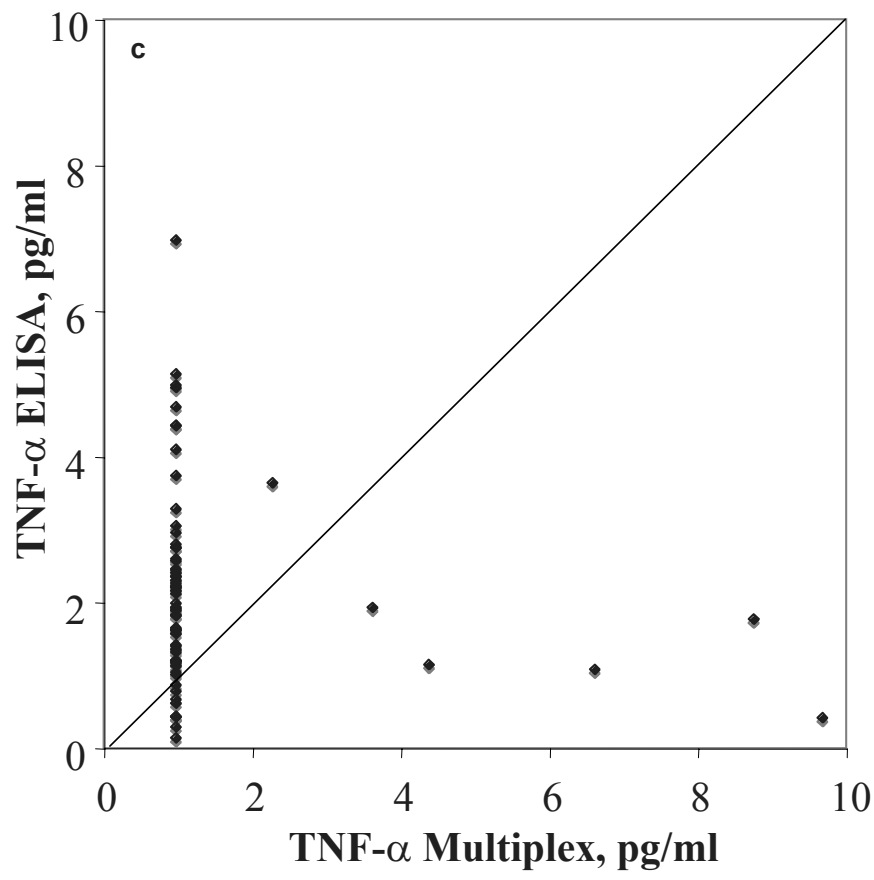

Fig. 1. a Scattergraph showing significant relationship between MCP-1 measured by ELISA and multiplex $(r=0.42)$. b Scattergraph showing poor correlation between IL- 6 measured by ELISA and multiplex (5 outliers removed from figure, $r=-0.11)$. c Scattergraph showing poor correlation between TNF- $\alpha$ measured by ELISA and multiplex techniques ( 5 outliers removed from figure, $\mathrm{r}=0.16$ ).

correlate with the independent marker of inflammation, CRP. Furthermore, while IL- 6 and MCP-1 values are within delectable limits, TNF- $\alpha$ is not detectable, and hence the multiplex assay is unable to provide values for all cytokines of interest within a single test in plasma samples from healthy subjects. For this reason, care should be taken when interpreting results obtained using the multiplex technique for human plasma samples.

Using the established ELISA technique, this study has shown that circulating MCP-1 is not associated with BMI, waist circumference, total fat mass, or abdominal fat mass in over- 

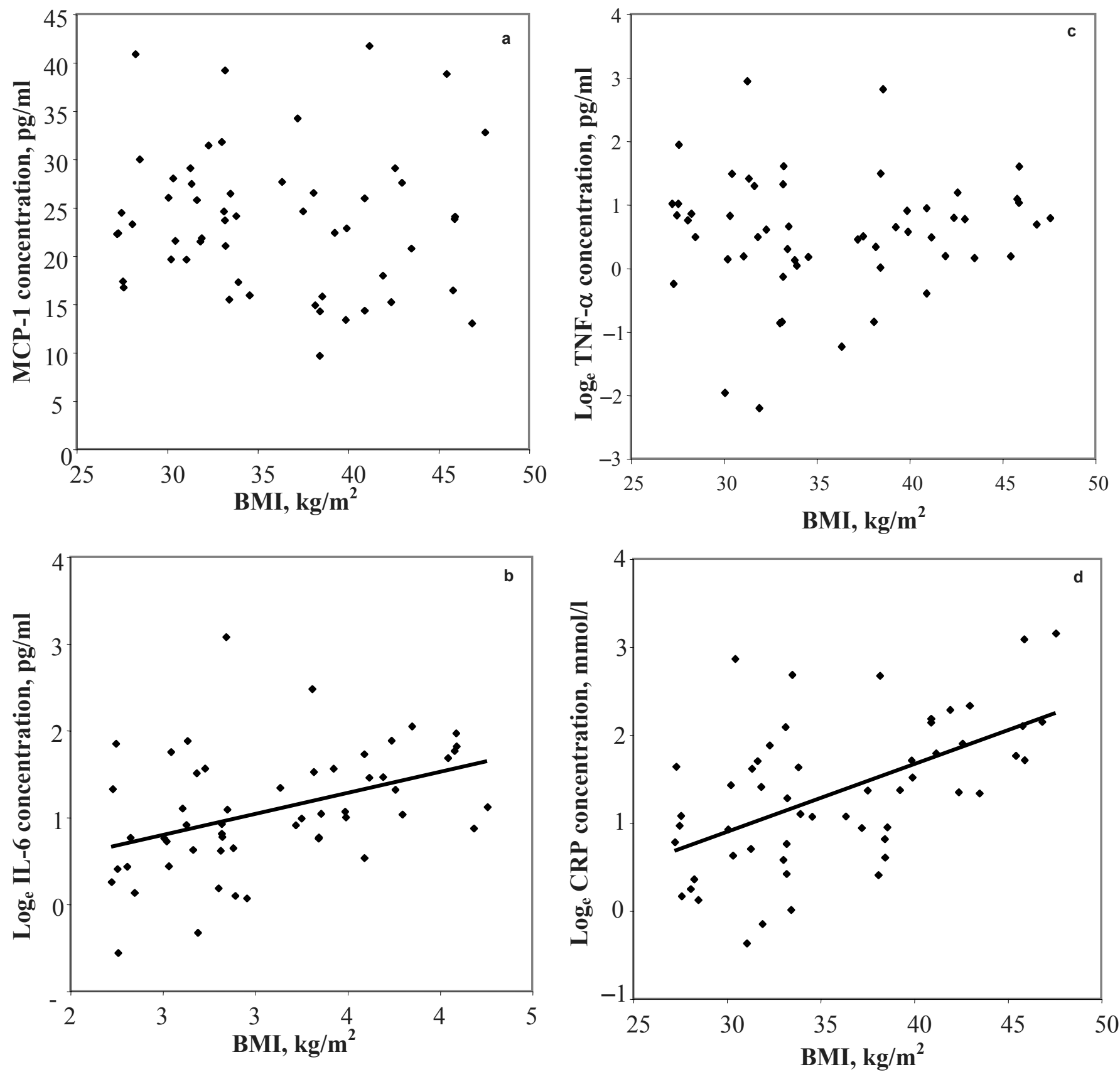

Fig. 2. a Relationship between obesity and circulating MCP-1 concentrations. b Relationship between obesity and circulating IL- 6 concentrations. c Relationship between obesity and circulating TNF- $\alpha$ concentrations. d Relationship between obesity and circulating CRP concentrations.

weight and obese insulin-resistant women, and does not decrease with moderate weight loss (mean $11.4 \mathrm{~kg}$ ). This result contrasts with that of Christiansen et al. [16] who showed that MCP-1 in the circulation was significantly correlated with BMI and decreased significantly with substantial weight loss (mean $18.9 \mathrm{~kg}$ ). However, our study population was much larger with 54 subjects, compared to 8 subjects in the previous cross sectional analysis and 23 in the weight loss analysis. Subjects had a similar range of adiposity. In our study, subjects were studied after a 12-week period of weight maintenance at the lower weight, and data from a weight-stable control group was also analysed.

The results of the present study also contrast with the study by Kim et al. [18], which showed a significant association between circulating MCP-1 and waist circumference in Korean men and women. In their study, the correlation appears to be driven by 4 subjects with MCP-1 concentrations more than 2-fold greater than any measured in the present study. The present 
study of Caucasian women does not include any lean subjects but covers a wider range of obesity (mean $35.8 \mathrm{vs.} 30.6 \mathrm{~kg} / \mathrm{m}^{2}$ ), with 11 subjects with a BMI greater than $40 \mathrm{~kg} / \mathrm{m}^{2}$.

A number of studies have shown that adipose tissue MCP-1 mRNA is correlated with obesity $[8,16,19]$ and reduced with substantial weight losses, such as those seen following bariatric surgery [8]. Further, depot-specific differences in adipose tissue MCP-1 expression have been shown [20]. While it was not possible to measure adipose tissue MCP-1 mRNA in this study, taken together these data suggest that circulating MCP1 may not be representative of the local adipose tissue inflammatory environment. This explanation is consistent with the action of MCP-1 in recruiting macrophages to the local area, causing them to infiltrate the adipose tissue, which in turn may promote inflammation both locally and systemically.

In the present study, the circulating adipokines IL-6, TNF- $\alpha$, and CRP were also measured. Similar to MCP-1, TNF- $\alpha$ was not significantly correlated with obesity or reduced with weight loss. It has previously been suggested that TNF- $\alpha$ has a greater role in promoting local inflammation and stimulating production of other inflammatory mediators [21]. In contrast, both IL-6 and CRP were significantly correlated with all measures of obesity, and significant reductions in CRP were shown with moderate weight loss. CRP has often been reported to be associated with obesity $[22,23]$ and has been used as a marker of inflammation and shown to be a predictor of obesity-related disease in many large scale prospective studies [24-27].
Further, CRP seems to be a stronger predictor of metabolic disease than the cytokine that stimulates its production, IL-6, supporting a role as a circulating marker of obesity-related inflammation $[25,26]$.

In conclusion, this study shows that in obese women circulating MCP-1 and TNF- $\alpha$ are not associated with indices of adiposity, nor are they reduced with moderate weight loss. This data suggests that these may not be useful markers of obesityrelated inflammation at a whole-body level. In contrast, IL-6 and CRP may be more useful circulating markers of inflammation.

\section{Acknowledgements}

We thank Kate Guberg and Ian Halsall who contributed to sample analysis, Joanne Rothwell, Jennifer Cooke, and Nicola McLean who contributed to sample collection, and Mark Chatfield and Carmel Moore for advice on the analysis of data from the 2 methods. This study was funded by the Medical Research Council.

\section{Author Contributions}

L.M. Browning and J.D. Krebs were responsible for study design, data collection, data analysis, and writing the manuscript. S.A. Jebb was involved in study design, data analysis, and writing the manuscript. E. Magee was involved in data collection, analysis, and reviewing the manuscript. G. Frühbeck was involved in data analysis and reviewing the manuscript.

\section{References}

1 Kern PA, Ranganathan S, Li C, Wood L, Ranganathan G: Adipose tissue tumor necrosis factor and interleukin-6 expression in human obesity and insulin resistance. Am J Physiol Endocrinol Metab 2001;280:E745-751.

- Tsigos C, Kyrou I, Chala E, Tsapogas P, Stavridis JC, Raptis SA, Katsilambros N: Circulating tumor necrosis factor alpha concentrations are higher in abdominal versus peripheral obesity. Metabolism 1999;48:1332-1335.

3 Browning LM, Jebb SA, Mishra GD, Cooke JH, O'Connell MA, Crook MA, Krebs JD: Elevated sialic acid, but not CRP, predicts features of the metabolic syndrome independently of BMI in women. Int J Obes 2004:28:1004-1010.

4 Hotamisligil GS, Shargill NS, Spiegelman BM: Adipose expression of tumor necrosis factor-alpha: direct role in obesity-linked insulin resistance. Science 1993;259:87-91.

5 Fried SK, Bunkin DA, Greenberg AS: Omental and subcutaneous adipose tissues of obese subjects release interleukin-6: depot difference and regulation by glucocorticoid. J Clin Endocrinol Metab 1998 ; 83:847-850.

6 Wellen KE, Hotamisligil GS: Obesity-induced inflammatory changes in adipose tissue. J Clin Invest 2003;112:1785-1788.

7 Weisberg SP, McCann D, Desai M, Rosenbaum M, Leibel RL, Ferrante AW Jr: Obesity is associated with macrophage accumulation in adipose tissue. $\mathrm{J}$ Clin Invest 2003;112:1796-1808
Cancello R, Henegar C, Viguerie N, Taleb S, Poitou C, Rouault C, Coupaye M, Pelloux V, Hugol D, Bouillot JL, Bouloumie A, Barbatelli G, Cinti S, Svensson PA, Barsh GS, Zucker JD, Basdevant A, Langin D, Clement K: Reduction of macrophage infiltration and chemoattractant gene expression changes in white adipose tissue of morbidly obese subjects after surgery-induced weight loss. Diabetes 2005;54:2277-2286

9 Bastard J-P, Jardel C, Bruckert E, Blondy P, Capeau J, Laville M, Vidal H, Hainque B: Elevated levels of interleukin- 6 are reduced in serum and subcutaneous adipose tissue of obese women after weight loss. J Clin Endocrinol Metab 2000;85:3338-3342.

10 Heilbronn LK, Noakes M, Clifton PM: Energy restriction and weight loss on very-low-fat diets reduce $\mathrm{C}$-reactive protein concentrations in obese, healthy women. Arterioscler Thromb Vasc Biol 2001;21:968-970.

11 Ziccardi P, Nappo F, Giugliano G, Esposito K, Marfella R, Cioffi M, D'Andrea F, Molinari AM, Giugliano D: Reduction of inflammatory cytokine concentrations and improvement of endothelial functions in obese women after weight loss over one year. Circulation 2002;105:804-809.

12 Laimer M, Ebenbichler CF, Kaser S, Sandhofer A, Weiss H, Nehoda H, Aigner F, Patsch JR: Markers of chronic inflammation and obesity: a prospective study on the reversibility of this association in middle-aged women undergoing weight loss by surgical intervention. Int J Obes Relat Metab Disord 2002;26:659-662.
13 Krebs JD, Evans S, Cooney L, Mishra GD, Fruhbeck G, Finer N, Jebb SA: Changes in risk factors for cardiovascular disease with body fat loss in obese women. Diabetes Obes Metab 2002;4: 379-387.

14 Case CC, Jones PH, Nelson K, O'Brian Smith E, Ballantyne CM: Impact of weight loss on the metabolic syndrome. Diabetes Obes Metab 2002;4: 407-414.

15 Pereira JA, Lazarin MA, Pareja JC, de Souza A, Muscelli E: Insulin resistance in nondiabetic morbidly obese patients: effect of bariatric surgery. Obes Res 2003;11:1495-1501.

16 Christiansen T, Richelsen B, Bruun JM: Monocyte chemoattractant protein-1 is produced in isolated adipocytes, associated with adiposity and reduced after weight loss in morbid obese subjects. Int J Obes (Lond) 2005;29:146-150.

17 Krebs JD, Browning LM, McLean NK, Rothwell JL, Mishra GD, Moore CS, Jebb SA: Additive benefits of long chain n-3 polyunsaturated fatty acids and weight-loss in the management of cardiovascular disease risk in overweight hyperinsulinaemic women. Int J Obes 2006;30:1535-1544.

18 Kim CS, Park HS, Kawada T, Kim JH, Lim D, Hubbard NE, Kwon BS, Erickson KL, Yu R: Circulating levels of MCP-1 and IL-8 are elevated in human obese subjects and associated with obesity-related parameters. Int J Obes (Lond) 2006;30:1347-1355. 
19 Dahlman I, Kaaman M, Olsson T, Tan GD, Bickerton AS, Wahlen K, Andersson J, Nordstrom EA, Blomqvist L, Sjogren A, Forsgren M, Attersand A, Arner P: A unique role of monocyte chemoattractant protein 1 among chemokines in adipose tissue of obese subjects. J Clin Endocrinol Metab 2005;90 :5834-5840.

20 Bruun JM, Lihn AS, Pedersen SB, Richelsen B Monocyte chemoattractant protein-1 release is higher in visceral than subcutaneous human adipose tissue (AT): implication of macrophages resident in the AT. J Clin Endocrinol Metab 2005;90: 2282-2289.

21 Mohamed-Ali V, Goodrick S, Rawesh A, Katz DR Miles JM, Yudkin JS, Klein S, Coppack SW: Subcutaneous adipose tissue releases interleukin-6, but not tumor necrosis factor-alpha, in vivo. J Clin Endocrinol Metab 1997;82:4196-4200.
22 Visser M, Bouter LM, McQuillan GM, Wener MH, Harris TB: Elevated C-reactive protein levels in overweight and obese adults. JAMA 1999;282: 2131-2135.

23 Pannacciulli N, Cantatore FP, Minenna A, Bellacicco M, Giorgino R, De Pergola G: C-reactive protein is independently associated with total body fat, central fat, and insulin resistance in adult women. Int J Obes Relat Metab Disord 2001;25:1416-1420.

24 Harris TB, Ferrucci L, Tracy RP, Corti MC, Wacholder S, Ettinger WH Jr, Heimovitz H, Cohen HJ, Wallace R: Associations of elevated interleukin-6 and C-reactive protein levels with mortality in the elderly. Am J Med 1999;106:506-512.
5 Ridker PM, Hennekens CH, Burling JE, Rifai N: CReactive protein and other markers of inflammation in the prediction of cardiovascular disease in women. N Engl J Med 2000;342:836-843.

26 Pradhan AD, Manson JE, Rifai N, Buring JE, Ridker PM: C-reactive protein, interleukin 6, and risk of developing type 2 diabetes mellitus. JAMA 2001; 286:327-334.

27 Freeman DJ, Norrie J, Caslake MJ, Gaw A, Ford I, Lowe GD, O'Reilly DS, Packard CJ, Sattar N: C-reactive protein is an independent predictor of risk for the development of diabetes in the West of Scotland Coronary Prevention Study. Diabetes 2002;51:1596-1600. 